\title{
EFEITO DA TEMPERATURA DO AR DE ADMISSÃO NO ATRASO DE IGNIÇÃO DE UM MOTOR A ETANOL DE IGNIÇÃO ASSISTIDA POR SUPERFÍCIE AQUECIDA
}

\author{
Rafael Hauckewitz Todaro ${ }^{1}$, Clayton Barcelos Zabeu ${ }^{2}$, Renato Romio ${ }^{3}$, \\ Antonio Luiz Pacifico ${ }^{4}$ \\ Instituto Mauá de Tecnologia \\ ${ }^{1}$ todaro@usp.br; ${ }^{2}$ clayton@maua.br; ${ }^{3}$ romio@ @aua.br; ${ }^{4}$ alpacifi@usp.br
}

\section{RESUMO}

Estudos recentes mostram que o uso de etanol para motores a combustão interna promete uma relação positiva entre a eficiência global e os aspectos atrelados às emissões de poluentes e de gases de efeito estufa. Motivado pela busca de melhor ciência sobre as propriedades do etanol como propelente de motores de combustão espontânea, o objetivo principal do presente trabalho consiste em verificar a influência da temperatura do ar de admissão no processo de combustão do etanol hidratado e do óleo diesel, especificamente no atraso de ignição e na duração de combustão. A técnica da superfície aquecida foi utilizada como meio para auxiliar o processo de ignição da mistura ar-etanol. O motor diesel SDE 1,3 L da General Motors, equipado uma central de gerenciamento eletrônico aberta e adequadamente adaptada foi utilizado como estudo de caso. Os parâmetros de combustão foram avaliados em dois casos, considerados a partir de uma condição de operação proposta para o etanol e para o diesel. Os resultados mostram que as propriedades da combustão do álcool são consideravelmente influenciadas pelo estado termodinâmico do ar na etapa de admissão, o que difere do comportamento verificado para o diesel. Em determinadas condições, o atraso de ignição na operação com etanol se mostrou mais de $60 \%$ maior do que com diesel e a relação entre as durações de combustão do álcool e do diesel é maior que $200 \%$.

\section{INTRODUÇÃO}

Os combustíveis de origem fóssil são utilizados em diversas áreas da economia e tiveram grande influência no processo de modernização da civilização, tornando-se indispensáveis em setores como transporte, indústria e diversas outras áreas que contam com conversão de energia química em potência útil [1]. Recentemente, devido à crescente preocupação com o meio ambiente, a fiscalização das emissões de motores de combustão 
interna é percebida de forma mais severa e a indústria automobilística passou a trabalhar constantemente com o desafio de desenvolver motores com alta eficiência de conversão energética e que respeitem, simultaneamente, os níveis de emissão de gases de efeito estufa regulamentados na última Conferência de Mudanças Climáticas das Nações Unidas [2]. Para tanto, estudos direcionados à pesquisa e desenvolvimento de combustíveis sustentáveis têm sido realizados com o objetivo de encontrar uma solução economicamente rentável, que seja renovável e que consiga respeitar os patamares máximos de emissão de Gases do Efeito Estufa já estabelecidos [3].

No cenário apresentado, há dois fortes candidatos capazes de atender às expectativas atuais: os motores diesel e o etanol. Os motores diesel têm alta eficiência de conversão de energia, elevado torque em relação aos motores que têm funcionamento regido pelo Ciclo Otto e oferecem vantagens sob o aspecto de knock e de consumo de combustível devido à alta taxa de compressão [4-6]. Entretanto, em contraponto à considerável eficiência, emitem elevados níveis de material particulado e $\mathrm{NO}_{\mathrm{X}}$ - elementos responsáveis por um dos maiores problemas de poluição contemporâneo [7-10]. Já o etanol surge como uma das melhores alternativas à adoção de um combustível renovável capaz de substituir os derivados do petróleo. Este álcool, além de ser oxigenado e livre de enxofre, tem grande potencial de produção e propriedades físico-químicas atrativas como o alto calor latente de vaporização, alta velocidade de queima e maior número de octanos se comparado à gasolina. Convenientemente, possui elevado potencial de redução de emissão de $\mathrm{NO}_{\mathrm{x}}$ e MP se utilizado como propelente de motores com ignição espontânea [11-15].

A fim de apresentar uma solução factível à atual necessidade da indústria em produzir motores com alta eficiência e baixos níveis de emissão de Gases do Efeito Estufa, várias pesquisas têm sido realizadas para identificar as melhores modificações construtivas aplicáveis a motores com ignição por compressão que tenham o etanol como combustível. Além da adoção de estratégias de modificação dos combustíveis, o amplo conhecimento sobre o processo de formação da mistura também é necessário [5,16]. De acordo com a literatura, algumas das técnicas adotadas para promover o uso de etanol em motores diesel são: mistura de combustíveis; injeção de álcool no coletor de admissão; injeção direta de etanol e óleo diesel na câmara de combustão; instalação de sistema de ignição por centelha e o método da superfície aquecida [17-19]. Todavia, vale destacar que o uso do etanol em motores diesel envolve algumas limitações como a redução das propriedades lubrificantes, a menor capacidade de ignição do combustível e o baixo poder calorífico comparado ao óleo diesel [14, 20-23].

A injeção de etanol no coletor de admissão permite percentuais de substituição de óleo diesel acima de $50 \%$ e requer todo o sistema de controle típico utilizado para realizar a injeção do etanol em motores Otto (central eletrônica e os periféricos como bomba de combustível, injetores e tanque para armazenamento). Já a injeção direta do diesel e do etanol na câmara de combustão possibilita a substituição de no máximo $90 \%$, se ambos os combustíveis forem injetados por sistemas de injeção independentes. No caso da 
técnica de mistura, a substituição do óleo diesel é inferior a 25\%, graças à separação de fases que ocorre por conta da baixa miscibilidade do etanol no combustível fóssil [13,18,23-26]. Nestes casos, a combustão é dada espontaneamente, isto é, sem a presença de centelha ou qualquer fonte de energia que favoreça o desencadeamento das reações de combustão. De acordo Gomes et al. [6] os efeitos da adição de etanol são dependentes das características construtivas do motor, do modo de operação e do respectivo percentual de substituição.

Segundo Moreal et al. [19], o processo de queima de combustíveis com baixo número de cetanas em motores com ignição espontânea não ocorre da mesma forma. Para promover a ignição da mistura, aditivos promovedores de autoignição, centelha e altas razões de compressão são os meios que podem ser utilizados para possibilitar o desenvolvimento da combustão. Uma forma alternativa às mencionadas é o método de ignição por superfície aquecida, que consiste na presença de uma superfície mantida em alta temperatura no interior da câmara de combustão (utilizando uma vela incandescente, por exemplo). Esta técnica é amplamente discutida por Jacob et al. [27] a partir de estudo no qual os autores utilizam uma técnica de imagens de alta velocidade para avaliar a ignição e a propagação de chama do etanol promovida pela presença de uma vela incandescente. Como conclusão, os autores apresentam os principais parâmetros que influenciam a ignição e mostram que o uso de uma superfície aquecida fornece condições estáveis de ignição do etanol nas condições de partida a frio - condição crítica devido à elevada temperatura de vaporização do etanol [3]. Argachoy e Pimenta [28] recomendam que a superfície aquecida seja posicionada na região do spray de combustível onde se estabelece a formação de uma chama de pré-mistura rica, para garantir que a elevada temperatura da vela incandescente possibilite que toda a mistura de ar e etanol seja queimada.

Os principais e mais marcantes efeitos do uso de etanol em motores diesel são o aumento do pico de pressão no interior do cilindro e o maior atraso de ignição, se considerada uma comparação entre a operação do motor com o óleo combustível e o álcool. Zhu et al. [29] identificaram que além das características mencionadas, a taxa de liberação de calor tem aumento diretamente proporcional à concentração de etanol na mistura ar-combustível e que o atraso de ignição mais pronunciado é esperado, devido ao menor número de cetano na mistura e à diminuição de temperatura local. Os autores apontam ainda que, por conta de o álcool contar com oxigênio em sua composição, a oxidação durante a queima é pronunciada, o que torna menor o tempo de combustão e eleva a eficiência térmica do motor. O mesmo pode ser verificado por Sarjovaara e Larmi [30]. Hulwan e Joshi [21] e Fang et al. [31] relatam também que a adição de etanol promove maior quantidade de combustível queimada na fase de combustão pré-misturada, graças à melhor homogeneidade da mistura ar-combustível que a baixa viscosidade propicia.

Vale destacar que o atraso de ignição é definido por Heywood [32] como o intervalo de tempo entre o início da injeção e o início da combustão, sendo o primeiro medido pelo instante no qual o injetor é acionado e o último igual ao instante no qual ocorre o máximo 
valor da derivada de primeira ordem da curva de pressão em relação ao ângulo do virabrequim, uma vez que a taxa de liberação de energia é diretamente proporcional à taxa de variação da pressão na câmara de combustão. Jamuwa et al.[33] classificam o atraso de ignição como um parâmetro importante dos motores de ignição por compressão pelo fato de estar relacionado à vários aspectos, tais como a eficiência térmica, a falha de ignição (misfire), a suavidade de operação e as emissões de poluentes. Além disso, os autores destacam que a temperatura e pressão da mistura, a relação ar-combustível e as propriedades do combustível são as principais variáveis que influenciam o atraso de ignição, sendo a sua respectiva duração um reflexo das características químicas do combustível. A Figura 1 mostra um exemplo gráfico de cálculo do atraso de ignição proposto a partir das curvas de pressão de combustão e de taxa de liberação de calor aparente.

Figura 1 - Curvas de pressão, de taxa de liberação de calor aparente e perfil de levantamento de agulha do injetor em função da posição do virabrequim de um motor diesel. Na imagem, I.D. é a abreviação de ignition delay. Fonte: Adaptado de [32].

Ângulo do virabrequim - APMS

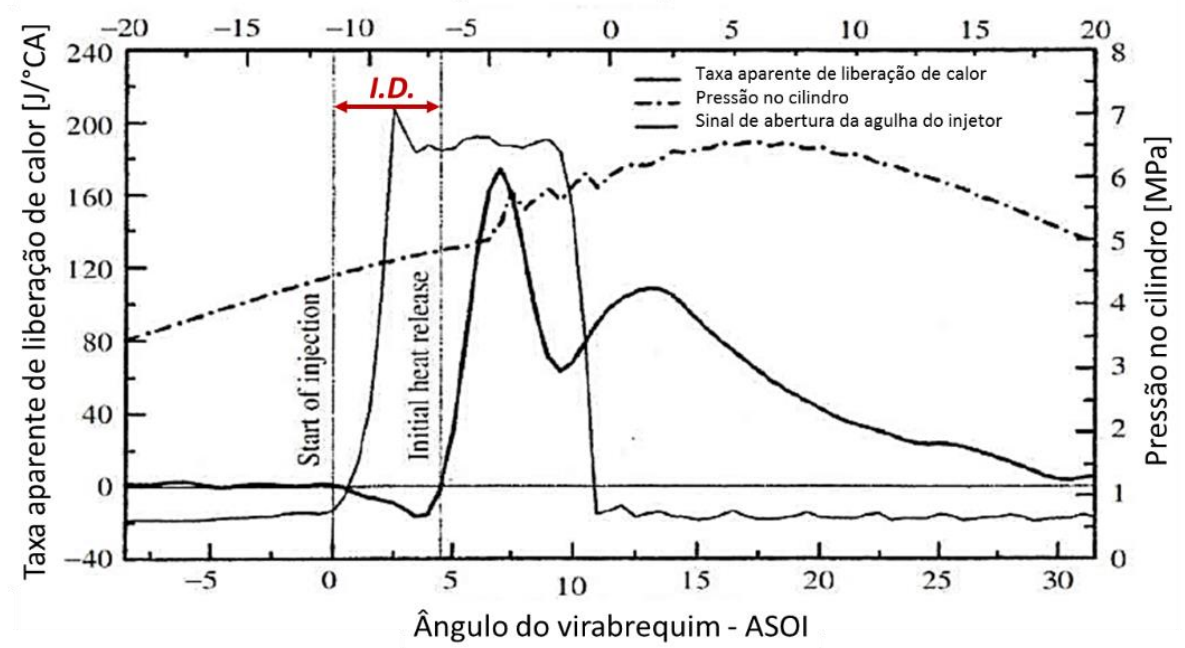

Segundo Heywood [32], a pressão e a temperatura são responsáveis por influenciar o atraso de ignição de acordo como o efeito que causam à mistura durante o período de atraso da combustão frente a injeção. Essencialmente, o autor mostra que quanto maior for a pressão e/ou a temperatura do ar admitido, menor será o ignition delay. A Figura 2 mostra a dependência que o atraso de ignição tem em relação ao estado termodinâmico do ar admitido e à carga do motor.

O presente trabalho tem o objetivo de avaliar o efeito que o combustível e a temperatura do ar de admissão exercem sobre o atraso de ignição de um motor diesel sobrealimentado, capaz de ser operado com diesel comercial e etanol hidratado, e que conta com sistema capaz de assistir a ignição através de uma superfície aquecida. Foram avaliados os níveis de pressão no interior do cilindro e alguns aspectos atrelados à combustão, como a taxa de liberação de calor, o atraso de ignição e a duração de combustão. 
Figura 2 - Efeito da pressão e temperatura do ar admitido e da carga no atraso de ignição de um motor diesel com injeção direta, mantido a 1980 rpm. (a) motor naturalmente aspirado e sobrealimentado (2 bar de pressão absoluta); temperatura de admissão $T_{i}=25^{\circ} \mathrm{C} ; C N=50$. (b) motor naturalmente aspirado $T_{i}=25^{\circ} \mathrm{C}$ e $T_{i}=66^{\circ} \mathrm{C}$; $C N=34$ e $C N=50$. Fonte: Adaptado de [32].

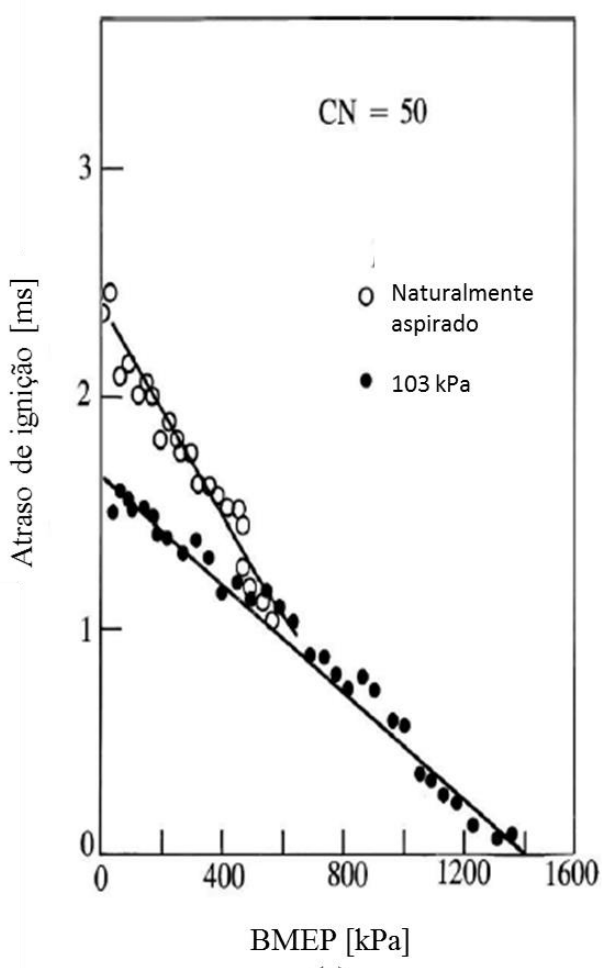

(a)

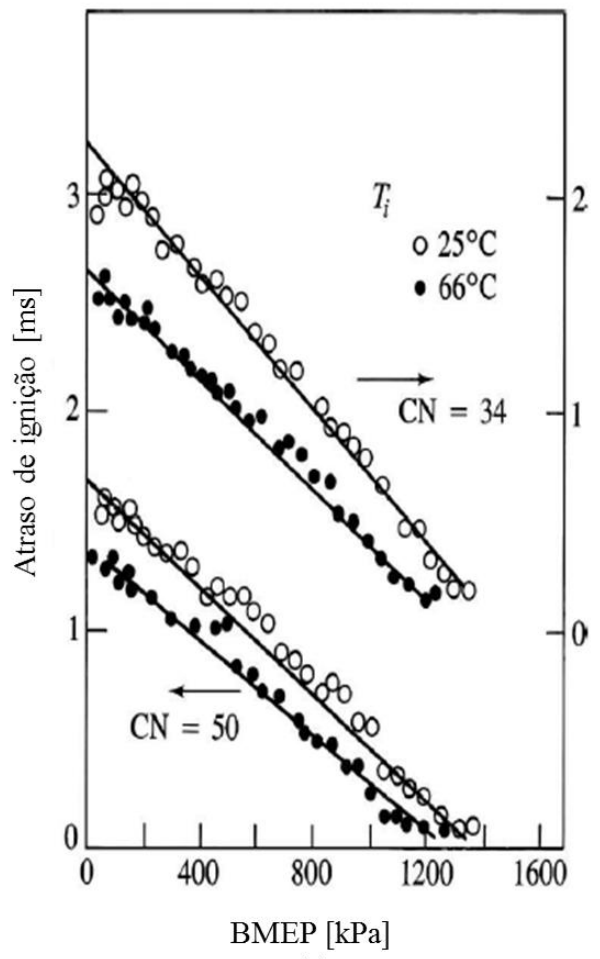

(b)

\section{METODOLOGIA EXPERIMENTAL}

Os testes realizados durante o desenvolvimento do presente trabalho foram executados no Centro de Pesquisas do Instituto Mauá de Tecnologia, localizado em São Caetano do Sul - SP. O banco de provas disponibilizado pelo Instituto conta com sistemas automatizados de controle dos regimes do motor e de aquisição de dados e oferece um dinamômetro elétrico ativo, fabricado pela empresa RAM do Brasil Ltda., modelo RAM - NBR 447250TS2, que oferece potência máxima de frenagem de $180 \mathrm{~kW}$ e possui rotação e torque máximo de $6800 \mathrm{rpm}$ e $400 \mathrm{Nm}$, respectivamente. Os ensaios foram conduzidos em um motor diesel, disponibilizado pela General Motors, com quatro cilindros. As estratégias de calibração e o controle do motor foram realizadas a partir das unidades abertas de controle eletrônica (ECU) modelos M250 e S070, do fabricante Pi Innovo $^{\mathrm{TM}}$.

Todas as condições de contorno para o funcionamento seguro do motor foram controladas de acordo com as faixas normais de trabalho recomendadas pelo fabricante. A Tabela 1 sumariza as principais especificações e características geométricas do motor utilizado. 
Tabela 1 - Características do motor diesel utilizado. Fonte: Adaptado de [19].

\begin{tabular}{ll}
\hline PARÂMETRO & TIPO OU MAGNITUDE \\
\hline Fabricante / Modelo & General Motors / SDE 1.3 L \\
Deslocamento & $1248 \mathrm{~cm}^{3}$ (4 cilindros) \\
Diâmetro / Curso & $69,6 \mathrm{~mm} / 82 \mathrm{~mm}$ \\
Relação de compressão & $18,1 \pm 0,4$ \\
Potência máxima & $51 \mathrm{~kW}(70 \mathrm{cv}) @ 4000 \mathrm{rpm}$ \\
Torque máximo & $180 \mathrm{Nm} \mathrm{@} \mathrm{1750} \mathrm{rpm}$ \\
Ordem da injeção & $1-3-4-2$ \\
Marcha lenta & $830 \pm 50 \mathrm{rpm}$ \\
Controle de válvula & DOHC com tucho hidráulico \\
Sistema de Injeção & Common Rail \\
\hline
\end{tabular}

Os ensaios foram realizados na rotação de máximo torque e as medições referentes à análise de aspectos atrelados à combustão foram feitas em apenas um dos quatro cilindros (neste caso, o cilindro 4). Termopares do tipo K, do fabricante Contemp ${ }^{\circledR}$, foram utilizados para adquirir a magnitude das temperaturas de admissão e escape, do fluido de arrefecimento na entrada e saída do motor e do óleo lubrificante. Para mensurar as pressões em diversos pontos de interesse foram empregados transdutores de pressão, fabricados pela empresa Druck ${ }^{\circledR}$, modelos PTX 1000 e PTX 7200. A temperatura do ar admitido pelo motor foi determinada por um trocador de calor do tipo ar/água, que utiliza água fornecida por uma unidade de resfriamento modelo MSW-45-RI-220/CT, do fabricante Mecalor ${ }^{\circledR}$. A partir deste conjunto, a temperatura de admissão do ar pode ser variada de $30{ }^{\circ} \mathrm{C}$ a $70{ }^{\circ} \mathrm{C}$ nos ensaios com etanol e de $40^{\circ} \mathrm{C}$ a $90^{\circ} \mathrm{C}$ nos testes com diesel. Em ambos os casos o incremento de temperatura foi constante e igual a $10{ }^{\circ} \mathrm{C}$.

A pressão instantânea no interior do cilindro estudado foi mensurada através de um sensor piezoelétrico modelo 6052C, fabricado pela Kistler Instrument Corporation, implantado no cabeçote do motor e conectado à câmara através de um canal indicador. O sensor possui sensibilidade de 21,65 pC/bar e tem o sinal amplificado pelo amplificador de carga AVL INDIMICRO. Os dados de pressão foram adquiridos em base angular por meio de um sistema AVL INDIMODUL, que tem como referência o sinal adquirido por um encoder tipo incremental modelo AVL 365C01. Todas as informações de pressão e taxa de liberação de calor adquiridos foram processadas e analisadas por um sistema de indicação comercial, o AVL INDICOM. Para eliminação do ruído gerado pelas frequências de ressonância produzidas no canal indicador, todas as curvas de pressão foram devidamente filtradas com frequência de corte de $1.000 \mathrm{~Hz}$.

Para operar o motor com etanol, uma vela incandescente modelo DuraSpeed, do fabricante Bosch $^{\circledR}$, foi empregada e é mostrada na Figura 3, à esquerda. É importante destacar que a presença deste componente foi essencial para o bom funcionamento do motor diesel operado com etanol, devido à real necessidade que o combustível apresenta 
em ter a combustão iniciada com o suporte da superfície aquecida. Neste caso, presumese que a presença da vela incandescente favorece a queima dos jatos de combustível mais próximos a ela, o que eleva a temperatura e pressão da câmara e possibilita a combustão espontânea do álcool. A Figura 3 mostra, destacado à direita, a disposição da vela incandescente em relação ao injetor e às válvulas de admissão e exaustão.

Figura 3 - Vela incandescente utilizada para assistir a ignição do etanol no motor diesel (à esq.) e disposição da vela próximo ao injetor e às válvulas de admissão e exaustão (à dir.). Fonte: Autor.
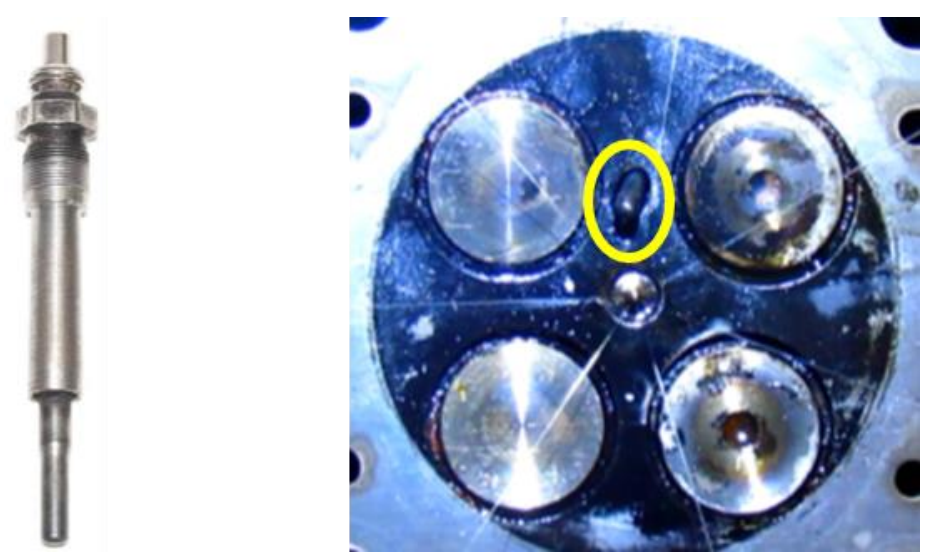

O início e o fim da combustão serão marcados pelos parâmetros CA10 e CA90, respectivamente. Ambos são provenientes da curva de taxa de liberação de calor e são responsáveis por representar o ângulo do virabrequim onde ocorreu $10 \%$ e $90 \%$ de acúmulo do calor liberado, nesta ordem. No presente trabalho, o atraso de ignição foi determinado pela diferença entre o CA10 e o SOI. A duração de combustão foi determinada pela diferença entre CA90 e CA10. Durante os ensaios, a rotação do motor foi mantida constante em 1750 rpm e a aquisição dos dados foi realizada após o motor atingir o regime permanente, este marcado pela estabilização das temperaturas de admissão e exaustão do ar e do fluido de arrefecimento.

\section{RESULTADOS E DISCUSSÃO}

Para realizar os testes no motor diesel SDE 1.3 utilizando etanol hidratado E95h (95\% de etanol anidro v/v + 5\% água v/v) e óleo diesel S10 B10 (10 ppm de enxofre e 10\% de biodiesel), duas estratégias de injeção foram adotadas. $\mathrm{O}$ objetivo de utilizar estratégias distintas consiste em obter, para cada combustível, o avanço de injeção que proporcionasse o início da combustão próximo ao ponto morto superior. A quantidade de combustível adicionada em cada caso foi condicionada ao limite de pressão de cilindro máxima na ordem de 140 bar. Como resultado, o ponto que representava a condição supracitada do motor com etanol foi atingido ao considerar o início da injeção em $14^{\circ}$ APMS, enquanto para o diesel, o SOI foi em $9^{\circ}$ APMS, considerando um determinado tempo de injeção em cada caso e evento único de injeção por ciclo. 
Para verificar o comportamento que o atraso de ignição e os demais parâmetros atrelados à combustão possuem, cada estratégia foi utilizada para operar o motor tanto com etanol quanto com diesel. Deste modo, ambos os combustíveis foram avaliados fora da condição considerada como ideal. Os resultados obtidos serão apresentados em duas principais seções: Caso I - $9^{\circ}$ APMS; Caso II $-14^{\circ}$ APMS.

A Figura 4 indica o método de cálculo do atraso de ignição e da duração de combustão a partir das curvas indicadas obtidas em um ciclo. Nela são apresentadas as curvas de pressão de combustão (em vermelho), as curvas de taxa de liberação (em amarelo) e de liberação acumulada de calor (em azul) aparentes, além do sinal de comando do injetor (em branco). As linhas pontilhadas são utilizadas apenas para demarcar os intervalos utilizados para determinar o atraso de ignição e a duração de combustão a partir dos parâmetros CA10, CA90 e da posição do virabrequim onde a injeção é iniciada (SOI). Todos os gráficos e os parâmetros utilizados nas análises são compilados pelo software AVL INDICOM.

Figura 4 - Exemplo de cálculo do atraso de ignição e da duração de combustão a partir das curvas das grandezas indicadas. Fonte: Autor.

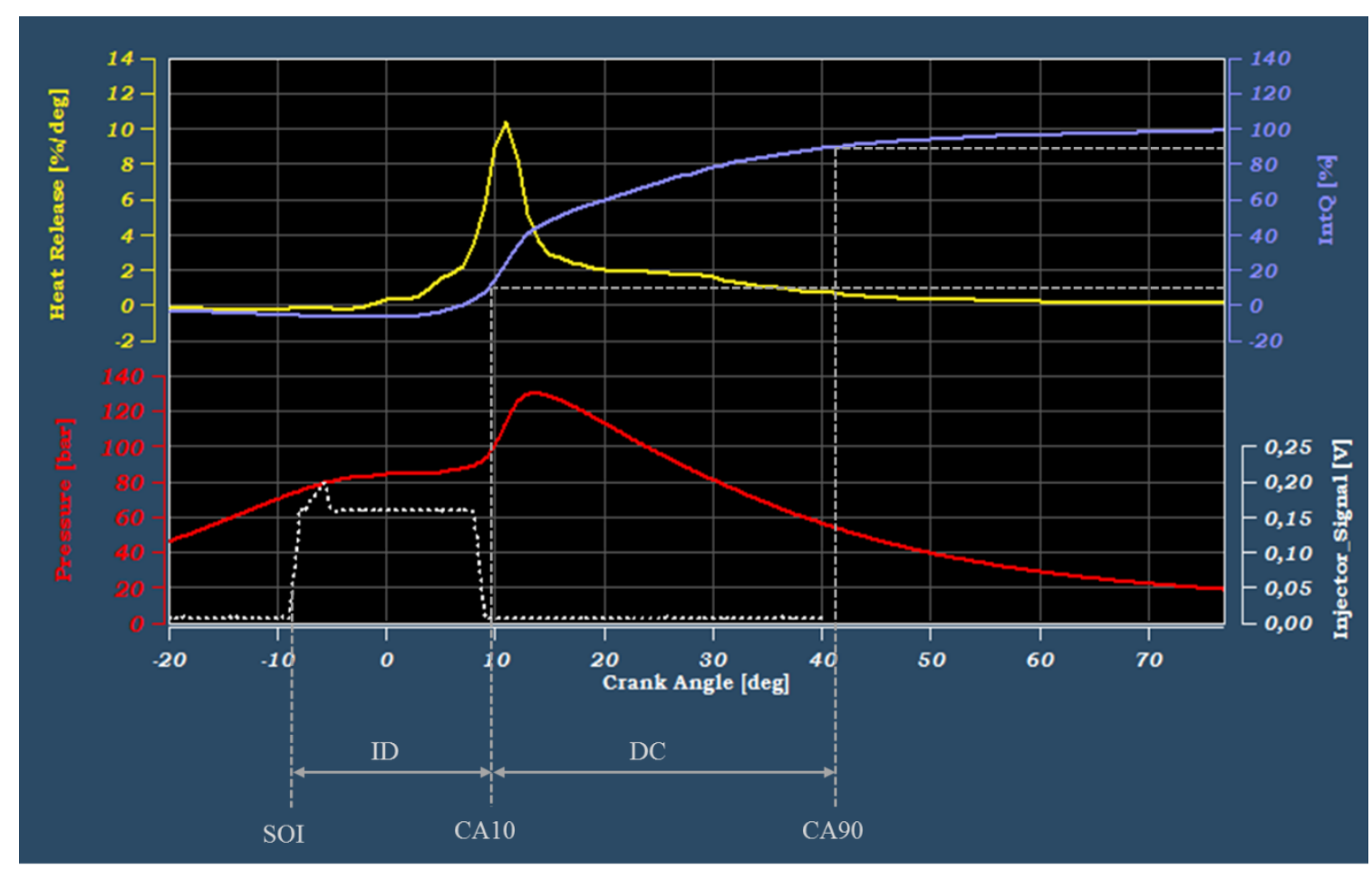

\subsection{CASO I - 90 APMS}

A Figura 5 mostra as curvas de taxa de liberação de calor aparente obtidas para o etanol e para o diesel a partir dos seis valores de temperatura de admissão considerados. Para todas as curvas referentes ao etanol, fica evidenciado que o aumento de temperatura é 
responsável pelo aumento dos picos e das derivadas de primeira ordem da curva de heat release na fase rápida da combustão. Como consequência a este comportamento, pode-se notar que o atraso de ignição e a duração de combustão do etanol tem influência significativa da temperatura de admissão do ar. Vale destacar que o etanol propicia ao motor maior atraso de ignição devido ao menor número de cetanos e ao efeito de resfriamento que oferece por conta do alto calor latente de evaporação que possui [5]. Além disso, percebe-se que o pico de pressão de combustão do álcool ocorre com maior atraso em relação ao diesel e que há elevações sutis de pressão entre --2,0 CA e 5,0 CA. Infere-se que as pequenas elevações iniciais nas curvas de taxas de liberação de calor devam ser consequência do início da combustão dos dois jatos que estão nas proximidades da vela e que são, por sua vez, responsáveis pela elevação da temperatura e pressão local.

Figura 5 - Curvas de taxa de liberação de calor aparente obtidas durante a operação do motor com etanol (superior) e com diesel (inferior) considerando a condição de injeção a $9^{\circ}$ APMS. Fonte: Autor.
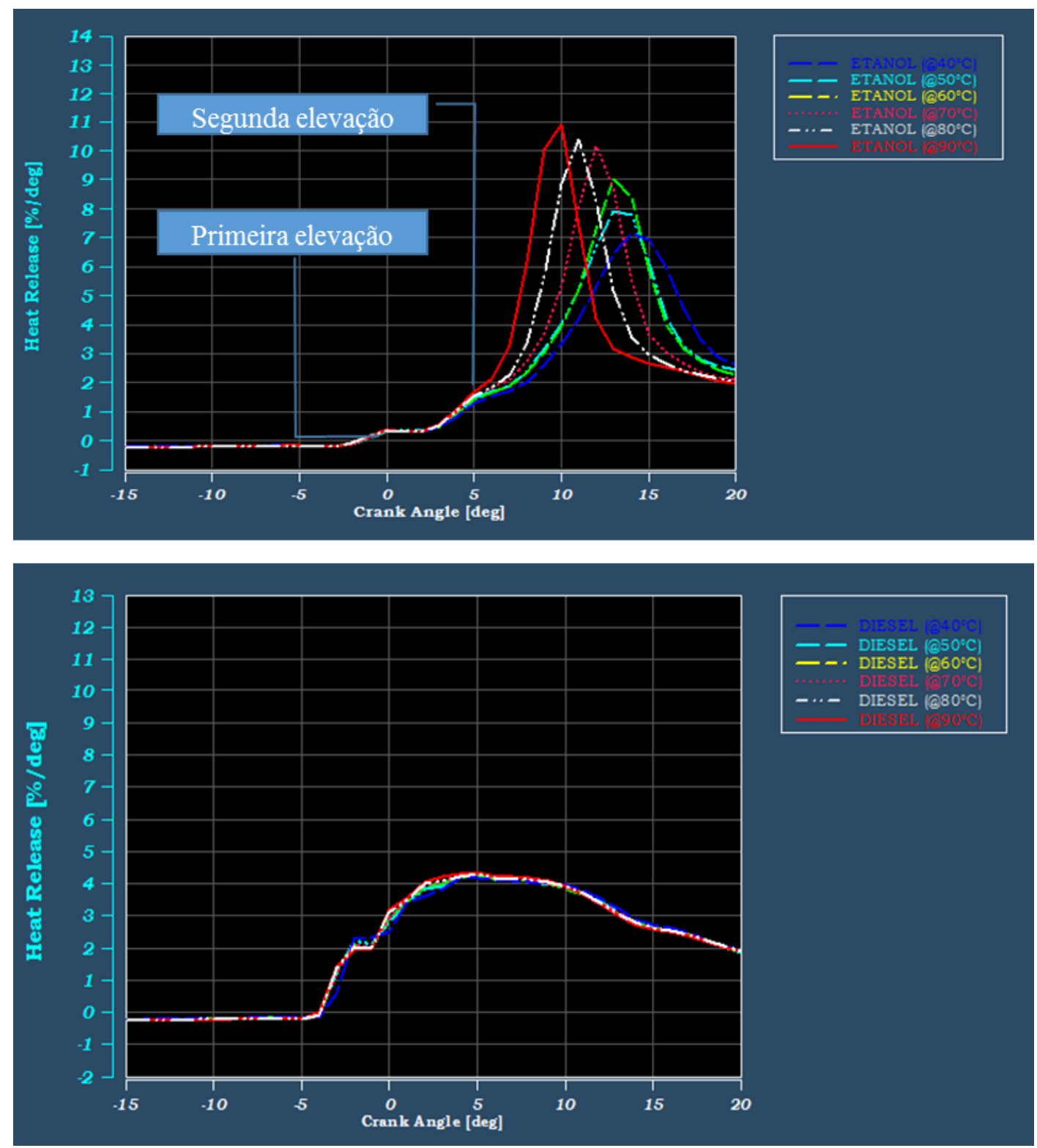
Com relação às curvas referentes a operação do motor com diesel, nota-se as todas as curvas de heat release obtidas estão praticamente sobrepostas. Deste modo, fica evidenciado que o estado termodinâmico do ar no coletor de admissão apresenta contribuição irrisória no atraso de ignição e na duração de combustão para esse motor que apresenta elevado swirl (o efeito do filtro digital aplicado ao sinal de pressão pode, entretanto, mascarar essa constatação). A Figura 6 apresenta a relação de dependência que existente entre a temperatura de admissão e o atraso de ignição do etanol e do diesel no motor utilizado. Analogamente, a Figura 7 mostra a tendência que a duração de combustão de ambos os combustíveis segue para as seis temperaturas testadas. A partir delas, nota-se que para todas as temperaturas em questão, a duração de combustão para o diesel supera a do etanol em até $22 \%$. Além disso, verifica-se que o atraso de ignição do etanol é consideravelmente maior do que o do diesel e sofre mais influência pela temperatura de admissão. De acordo com os dados revelados na Figura 6, verifica-se que o atraso de ignição do etanol é, em relação ao diesel, até $70 \%$ maior.

Figura 6 - Influência da temperatura de admissão no atraso de ignição do diesel e do etanol considerando a condição de injeção a $9^{\circ} \mathrm{APMS}$. Fonte: Autor.

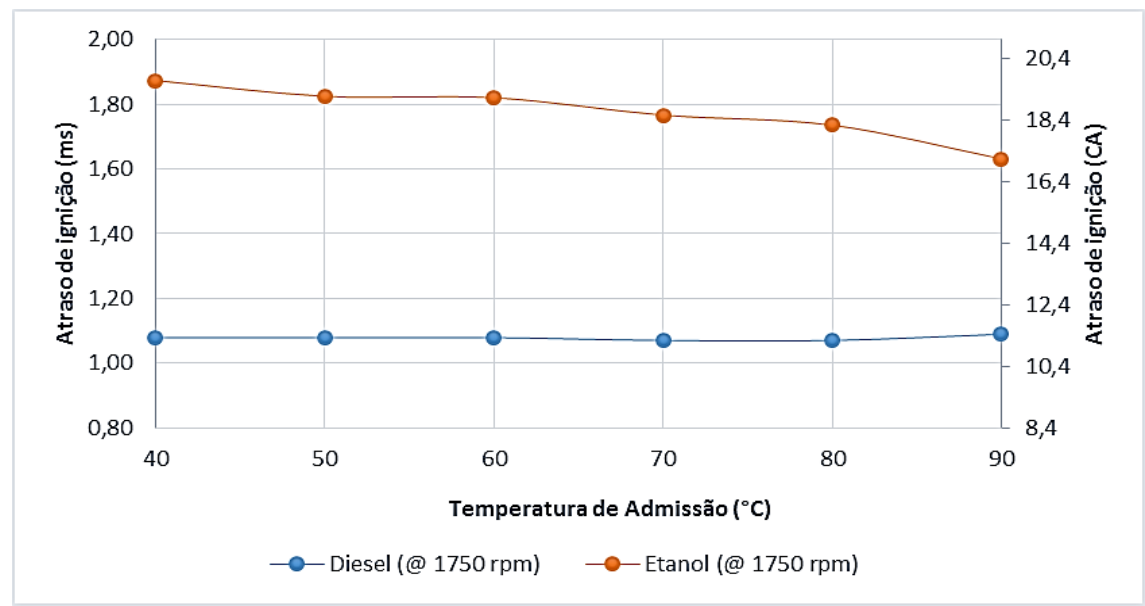

Figura 7 - Influência da temperatura de admissão na duração de combustão do diesel e do etanol considerando a condição de injeção a $9^{\circ} \mathrm{APMS}$. Fonte: Autor.

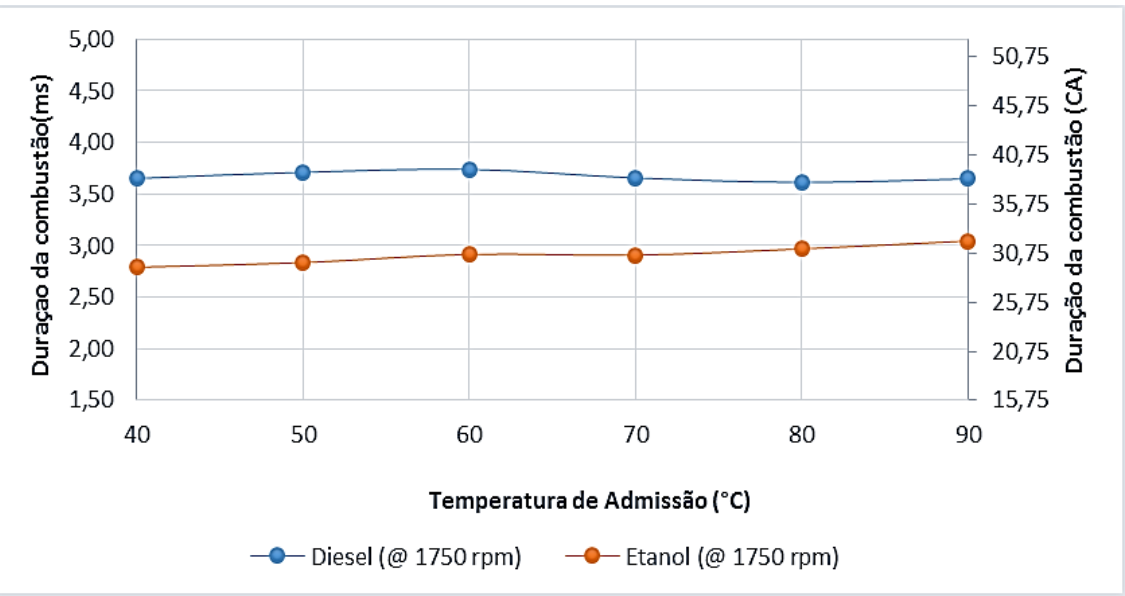


A Figura 8 apresenta as curvas médias de pressão de combustão, de taxa de liberação de calor aparente normalizada, de calor acumulado normalizado e o sinal de comando de abertura do injetor obtidas com etanol e com diesel, considerando temperatura de admissão igual a $70^{\circ} \mathrm{C}$. A partir da análise dos gráficos, percebe-se claramente que, embora o pico de pressão de combustão referente ao etanol é menor e mais atrasado frente ao diesel, a taxa com a qual a liberação de calor é sucedida durante o curso do pistão é maior para o etanol. É importante compreender também que a combustão acontece de forma mais tardia, devido ao maior atraso de ignição, simultaneamente ao fato de ocorrer de forma mais veloz se comparada ao diesel. A curva de calor acumulado representa explicitamente esta relação entre o maior atraso de ignição e a menor duração de combustão, uma vez que apresenta derivadas de primeira ordem mais acentuadas ao redor do ponto de inflexão, o que traz à tona a capacidade que o etanol detém de transferir calor mais rapidamente mesmo demorando mais para ter a própria combustão iniciada. Vale destacar que a pressão média efetiva indicada (IMEP) da curva média obtido para o diesel ficou compreendido entre 20,2 bar $\left(40^{\circ} \mathrm{C}\right)$ e 18,7 bar $\left(90^{\circ} \mathrm{C}\right)$ e para o etanol o intervalo foi de 20,2 bar $\left(40^{\circ} \mathrm{C}\right)$ e 18,6 bar $\left(90^{\circ} \mathrm{C}\right)$. A proximidade entre as pressões médias indicadas obtidas para os dois combustíveis é justificada pelo maior tempo de injeção considerado para o etanol, o que confere maior quantidade de combustível e, consequentemente, maior energia a ser convertida em potência.

Figura 8 - Sobreposição das curvas médias de pressão de combustão, taxa de liberação de calor aparente normalizada, calor acumulado aparente normalizado e sinal de comando de abertura do injetor obtidas com etanol e com diesel considerando temperatura do ar de admissão igual a $70^{\circ} \mathrm{C}$ e o início da injeção em 9, $0^{\circ}$ APMS. Para o etanol o término da injeção foi em $8,8^{\circ}$ DPMS e para o diesel, em $2^{\circ}$ DPMS. Fonte: Autor.

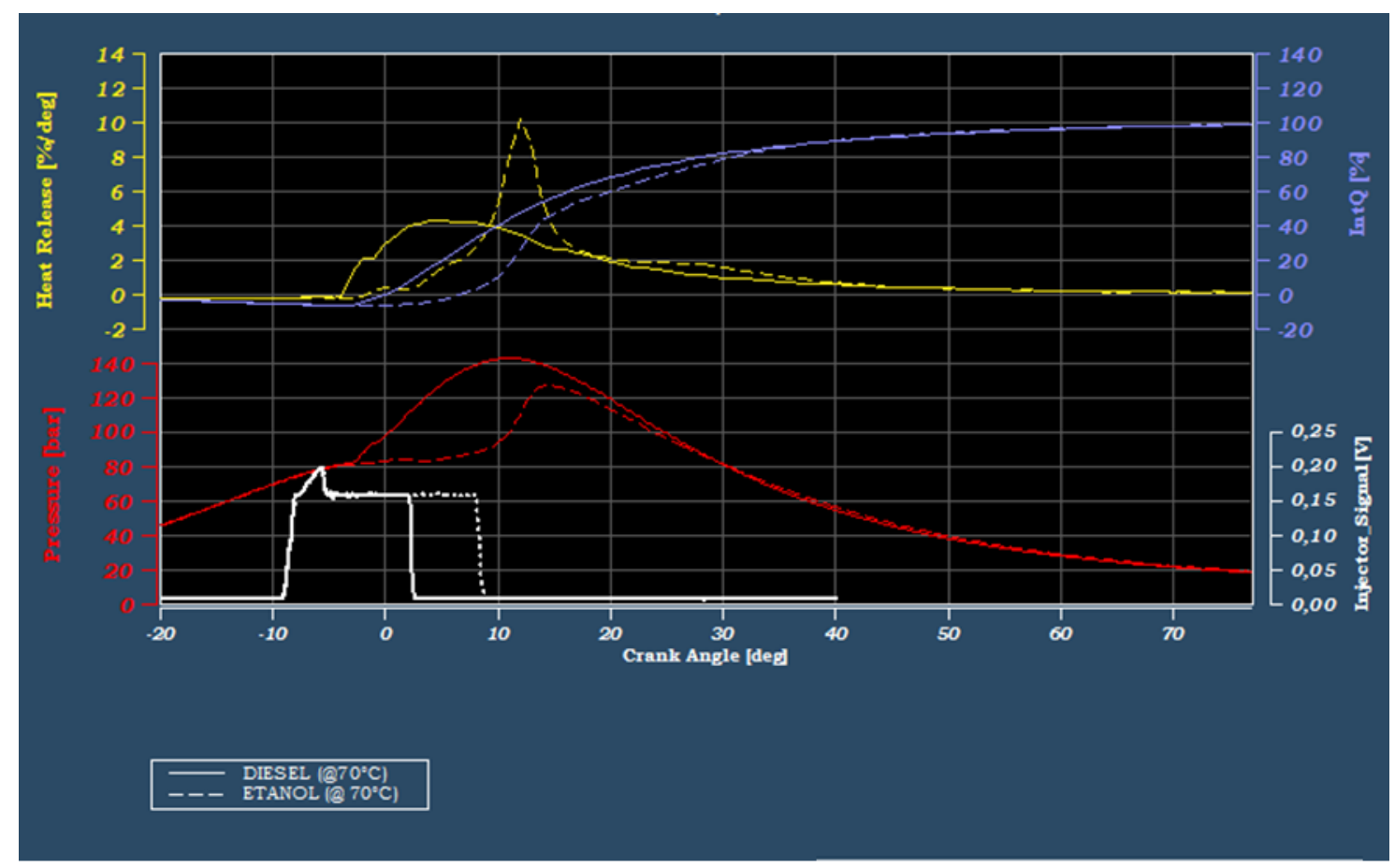




\subsection{CASO II - $14^{\circ}$ APMS}

A Figura 9 mostra as curvas de heat release obtidas para os combustíveis utilizados a partir dos cinco valores de temperatura de admissão considerados. Em todas as curvas referentes ao etanol, fica evidenciado novamente que o aumento de temperatura do ar de admissão é responsável pelo aumento dos picos e das derivadas de primeira ordem da curva de taxa aparente de liberação de calor na fase rápida da combustão. Deste modo, é coerente reafirmar que o atraso de ignição e a duração de combustão do etanol é influenciado significativamente pelo estado termodinâmico do ar admitido pelo motor.

Percebe-se ainda que há a mesma tendência de o pico de pressão de combustão do álcool se pronunciar com maior atraso em relação ao diesel e que as oscilações de pressão antes do aumento abrupto da taxa de transferência de calor também ocorrem. Para a última, cabe a mesma justificativa encontrada no Caso I, o que corrobora as hipóteses lançadas por Muller e Musculus [33]. Além disso, vale destacar que ao injetar o combustível de forma mais adiantada, os pontos de máximo local das curvas de heat release são maiores frente à condição $9^{\circ}$ APMS para o etanol.

Com relação às curvas referentes ao diesel, é possível notar que o comportamento temporal do heat release segue uma tendência diferente daquele visto na Figura 5. Notase que ao adiantar a injeção do diesel em uma condição "ótima" para o etanol, a taxa aparente de liberação de calor se mostra com três máximos locais e possui maiores derivadas na fase rápida da combustão, se comparado à condição $9^{\circ}$ APMS. Entretanto, verifica-se que os parâmetros atrelados à taxa de queima do diesel não apresentam suscetibilidade significativa às temperaturas impostas.

A Figura 10 apresenta a relação de dependência existente entre a temperatura de admissão e o atraso de ignição do etanol e do diesel na condição de injeção a $14^{\circ}$ APMS. A Figura 11 mostra a tendência que a duração de combustão de ambos os combustíveis possui quando o motor foi submetido às temperaturas de admissão variando de $30^{\circ} \mathrm{C}$ a $70^{\circ} \mathrm{C}$. A partir da análise dos gráficos apresentados nas Figuras 10 e 11, nota-se que para todas as temperaturas em questão o diesel continua superando o etanol no que se refere ao intervalo de tempo necessário para completar a combustão, embora tenha apresentado maior sensibilidade à temperatura e maiores magnitudes comparado à condição $9^{\circ} \mathrm{APMS}$. Já o etanol apresentou menor duração de combustão com relação à condição ótima para o diesel e se mostra diretamente influenciado pela temperatura com relação tanto ao atraso de ignição como à duração de combustão, novamente. De modo geral, os gráficos também mostram que o atraso de ignição do etanol pode superar em mais de 74\% o ID do diesel. Em contrapartida, a duração de combustão do diesel pode ser $70 \%$ mais lenta quando comparada ao álcool. 
Figura 9 - Curvas de taxa de liberação de calor aparente obtidas durante a operação do motor com etanol (superior) e com diesel (inferior) considerando a condição de injeção a $14^{\circ}$ APMS. Fonte: Autor.
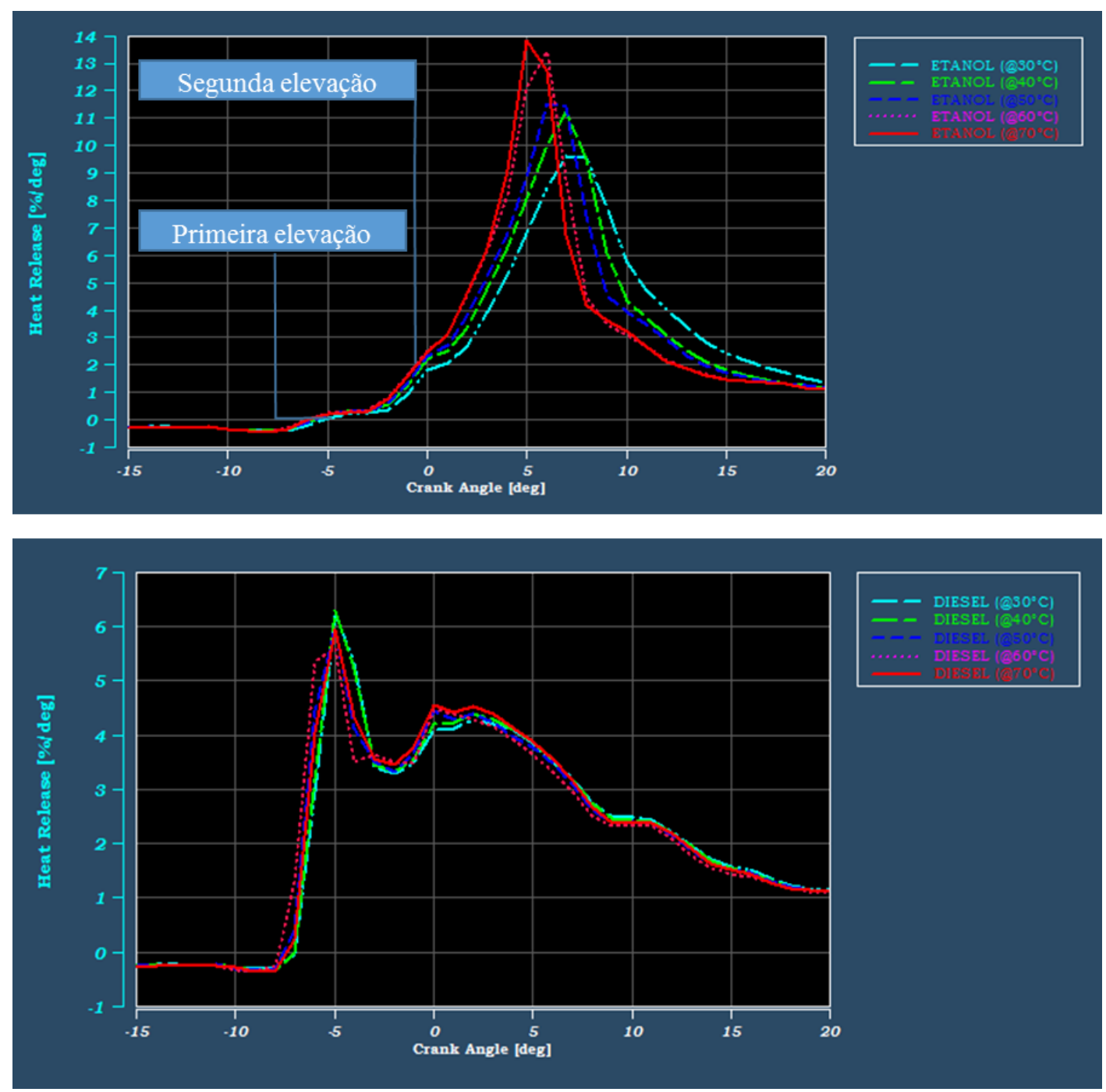

Figura 10 - Influência da temperatura de admissão no atraso de ignição do diesel e do etanol considerando a condição de injeção a $14^{\circ} \mathrm{APMS}$. Fonte: Autor.

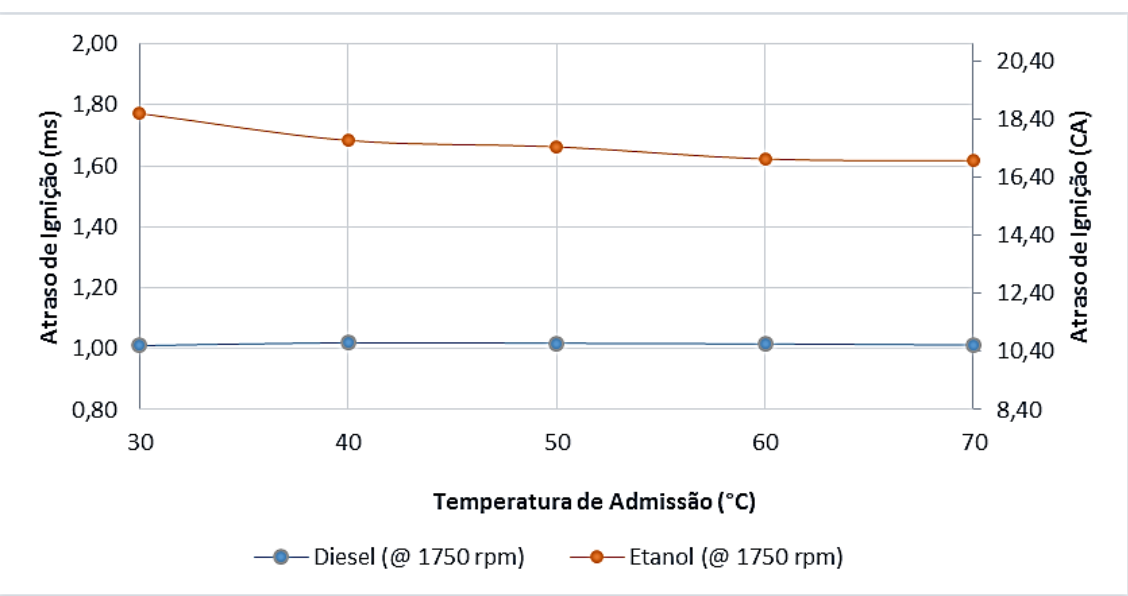


Figura 11 - Influência da temperatura de admissão na duração da combustão do diesel e do etanol considerando a condição de injeção a $14^{\circ}$ APMS. Fonte: Autor.

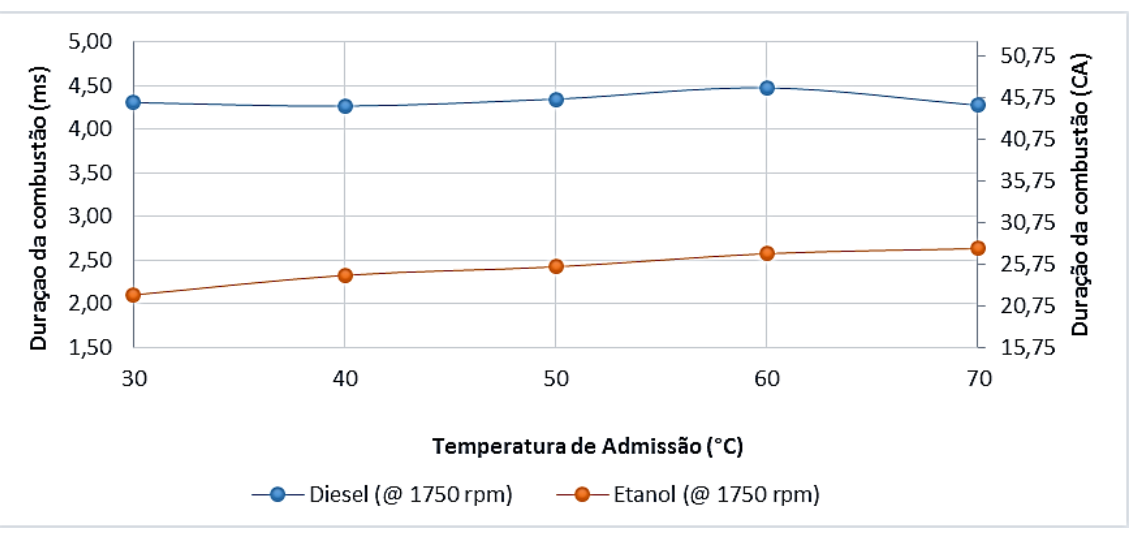

A Figura 12 mostra as curvas médias de pressão de combustão, de taxa aparente de liberação de calor normalizada, de calor acumulado normalizado e o sinal de abertura da agulha do injetor obtidas com etanol e com diesel, considerando a temperatura de admissão igual a $70^{\circ} \mathrm{C}$.

Figura 12 - Sobreposição das curvas médias de pressão de combustão, taxa aparente de liberação de calor normalizada, calor acumulado aparente normalizado e sinal de comando de abertura do injetor obtidas com etanol e com diesel considerando temperatura do ar de admissão igual a $70^{\circ} \mathrm{C}$, sendo o início da injeção em $14^{\circ} \mathrm{APMS}$ e o término em $2^{\circ}$ APMS (para ambos os combustíveis). Fonte: Autor.

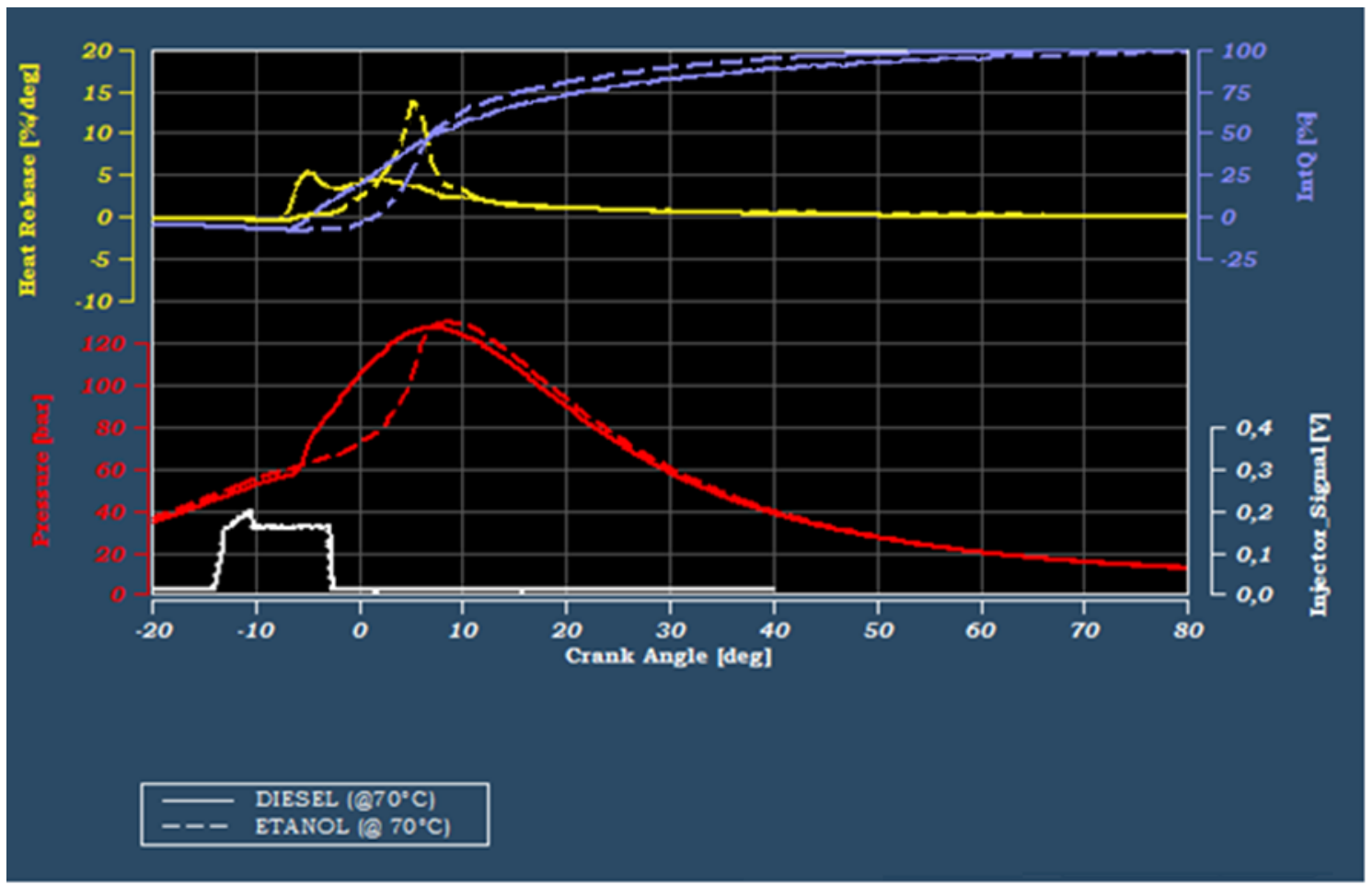


A partir da análise dos gráficos, nota-se que o pico de pressão de combustão referente ao etanol é ligeiramente maior e mais atrasado comparado ao diesel e que a velocidade com a qual acontece o processo de transferência de calor dentro do cilindro é maior para o etanol, o que lhe confere o menor tempo de combustão. Vale salientar que a curva de calor acumulado referente ao etanol supera a do diesel mais rapidamente nesta condição do que no Caso I. Além disso, destaca-se que os valores médios da pressão média efetiva indicada (IMEP) obtidos para o diesel ficaram compreendidos entre 15,01 bar $\left(30^{\circ} \mathrm{C}\right) \mathrm{e}$ 13,71 bar $\left(70^{\circ} \mathrm{C}\right)$ e para o etanol os extremos verificados são iguais a 14,07 bar $\left(30^{\circ} \mathrm{C}\right)$ e 13,75 bar $\left(70^{\circ} \mathrm{C}\right)$. Nesse caso, a duração de injeção para ambos os combustíveis foi mantida constante.

\section{CONCLUSÃO}

Etanol e óleo diesel foram utilizados como combustíveis de um motor de ignição por compressão para que o atraso de ignição, a duração de combustão e o comportamento das grandezas indicadas fossem julgados quanto à dependência com a temperatura de admissão. Dois casos foram propostos, sendo cada um deles determinados pelo instante de injeção que gerasse uma liberação de calor mais próxima da condição ideal em cada combustível. O parâmetro utilizado foi a escolha do SOI que possibilitasse, em cada caso, que a taxa de liberação de calor se iniciasse perto do PMS. Em ambos os casos estudados a relação entre o maior atraso de ignição e a menor duração de combustão do etanol comparado ao diesel ficou evidenciada, sendo que o primeiro é diminuído com o aumento da temperatura do ar de admissão, ao contrário do último. Consequentemente, as curvas de pressão sofrem alterações de posição tais que o acréscimo de temperatura, em geral, favorece o deslocamento do ponto de máxima pressão mais adiantado frente às curvas obtidas a partir da admissão de ar em temperaturas menores. A análise conjunta dos resultados de ambos os casos mostra a capacidade que o etanol detém de liberar calor mais rapidamente, embora demore mais para ter a própria combustão iniciada, o que não lhe confere um impedimento de ser utilizado em motores de ignição espontânea se a ignição for assistida por superfície aquecida. Consequentemente, entende-se que a mistura ar-etanol pode aumentar a eficiência térmica do motor devido à queima do combustível ser mais rápida, o que torna menor o tempo de troca térmica entre o gás e as paredes do cilindro.

\section{LISTA DE ABREVIATURAS}

$\begin{array}{ll}\text { APMS } & \text { Antes do ponto morto superior } \\ \text { ASOI } & \text { After the start of injection } \\ \text { BMEP } & \text { Brake Mean Effective Pressure }\end{array}$




$\begin{array}{ll}\text { CN } & \text { Cetane Number } \\ \text { DC } & \text { Duração da combustão } \\ \text { DPMS } & \text { Depois do ponto morto superior } \\ \text { ECU } & \text { Electronic Control Unit } \\ \text { ID } & \text { Ignition delay } \\ \text { IMEP } & \text { Indicated mean effective pressure } \\ \text { MP } & \text { Material particulado } \\ \text { PMS } & \text { Ponto morto superior } \\ \text { SOI } & \text { Start of injection }\end{array}$

\section{REFERÊNCIAS BIBLIOGRÁFICAS}

[1] IMRAN, A.; VARMAN, M.; MASJUKI, H.H.; KALAM, M.A. Review on alcohol fumigation on diesel engine performance and reduction of environment concerning emission. Renewable and Sustainable Energy Reviews, v. 26, p. 739-751, 2013.

[2] UNITED NATIOnS. Adoption of the Paris Agreement. Framew Conv Clim Change; 2015. p. 32.

[3] SARI, R. L.; NORA, M. D.; MARTINS, M. E. S.; ENZWEILER, H. J.; GOLKE, D.; DOS SANTOS, K.; "Investigação do uso de elevadas razões de compressão com etanol hidratado através da análise de liberação de calor", p. 569-581. Anais do XXV Simpósio Internacional de Engenharia Automotica - SIMEA 2017 São Paulo: Blucher, 2017. ISSN 2357-7592, DOI 10.5151/engpro-simea2017-43, ISSN 23577592, DOI 10.5151/engpro-simea2017-43

[4] REITZ, R.D.; DURAISAMY, G. Review of high efficiency and clean reactivity controlled compression ignition (RCCI) combustion in internal combustion engines. Progress in Energy and Combustion Science, v. 45, p. 12-71, 2015.

[5] OLIVEIRA, ALEX DE; SODRÉ, JOSÉ RICARDO, "Características da combustão de um motor diesel com injeção direta de misturas de óleo diesel e etanol e injeção indireta de etanol", p. 551-566 . Anais do XXIV Simpósio Internacional de Engenharia Automotica - SIMEA 2016. São Paulo: Blucher, 2016. ISSN 23577592, DOI 10.5151/engpro-simea2016-PAP7707

[6] GOMES, PAULO CÉSAR DE FERREIRA; MENDES, CARLOS FERNANDO; FRANIECK, ERWIN KARL; LOPES, GUSTAVO SANTOS; TEIXEIRA, ALYSSON FERNANDES; BAETA, JOSÉ GUILHERME COELHO; "Ethanol to improve the fuel conversion efficiency of s.i. engines in the brazilian market", p. 85100. Anais do XXV Simpósio Internacional de Engenharia Automotica - SIMEA 
2017. São Paulo: Blucher, 2017. ISSN 2357-7592, DOI 10.5151/engpro-simea201707

[7] SONG, JH; CHEENKACHORN, K.; WANG, J. G.; PEREZ, J.; BOEHMAN, A. Effect of oxygenated fuel on combustion and emissions in a light-duty turbo diesel engine. Energy Fuel, v. 16, p. 294-301, 2002.

[8] KOWALEWICZ A. Eco-diesel engine fuelled with rapeseed oil methyl ester and ethanol Part 3: Combustion processes. Transportation Science \& Technology, v. 21, p. 715723, 2006..

[9] WANG, LJ; SONG, RZ; ZOU, HB; LIU SH; ZHOU, LB. Study on combustion characteristics of a methanol-diesel dual-fuel compression ignition engine. Journal of Automobile Engineering, v. 222, p. 619-627, 2008.

[10] ZHANG, Z.H.; CHEUNG, C.S.; YAO, C.D. Influence of fumigation methanol on the combustion and particulate emissions of a diesel engine. Fuel, v. 111, p. 442-448, 2013.

[11] JEULAND, N., MONTAGNE, X., AND GAUTROT, X., "Potentiality of Ethanol As a Fuel for Dedicated Engine," Oil Gas Sci. Technol. - Rev. IFP 59(6):559-570, 2004, doi:10.2516/ogst:2004040

[12] HANSEN, Alan C.; ZHANG, Qin; LYNE, Peter W. L. Ethanol-diesel fuel blends a review. Bioresource Technology, v. 96, p. 277-285, 2005.

[13] SURAWSKI, N.C.; RISTOVSKI, Z.D., BROWN, R.J.; SITU, R. Gaseous and particle emissions from an ethanol fumigated compression ignition engine. Energy Conversion and Management, v. 54, p. 145-151, 2012.

[14] ZHU, L.; CHEUNG, C.S.; ZHANF, W.G.; HUANG, Zhen. Emissions characteristics of a diesel engine operating on biodiesel and biodiesel blended with ethanol and methanol. Science of the Total Environment, v. 408, n. 4, p. 941-921, 2010.

[15] BRITO JR., R.F.; MARTINS, C.A. Experimental analysis of a diesel engine operating in Diesel-Ethanol Dual-Fuel mode. Fuel, v. 134, p. 140-150, 2014.

[16] PEDROZO, V.B.; MAY, I.; NORA, M.D.; CAIRNS, A.; ZHAO, H. Experiments analysis of ethanol dual-fuel combustion in a heavy-duty diesel engine: An optimization at low load. Applied Energy, v. 165, p. 166-182, 2016.

[17] BALLI, O.; HAYDAR, A.; ARIF, H. Thermodynamic and Thermoeconomic analysis of a trigeneration (TRIGEN) system with a gas-diesel engine: Part II An application. Energy Conversion and Management, v. 51, p. 2260-2271, 2010.

[18] BORETTI, A. Advantages of converting Diesel engines to run as dual fuel ethanolDiesel. Applied Thermal Engineering, v. 47, p. 1-9, 2012.

[19] MOREAL, V. F. S.; CARVALHO, R. F.; ZABEU, C. B.; ROMIO, R. Aplicação da técnica de superfície aquecida em motores de combustão espontânea com utilização de etanol visando redução de emissão de $\mathrm{CO}_{2}$ e aumento de eficiência. Anais do XXVI Simpósio Internacional de Engenharia Automotica - SIMEA 2018 São Paulo: Blucher, 2018. 
[20] TSANG, K.S.; ZHANG Z.H.; CHEUNG, C.S., CHAN, T.L. Reducing Emissions of a Diesel Engine Using Fumigation Ethanol and a Diesel Oxidation Catalyst. Energy Fuel, v. 24, p. 6156-6165, 2010.

[21] HULWAN, D.B.; JOSHI, S.V. Performance, emission and combustion characteristic of a multicylinder DI diesel engine running on diesel-ethanol-biodiesel blends of high ethanol content. Applied Energy. v. 88, n. 12, p. 5042-5055, 2011.

[22] LI, X.; QIAO, X., ZHANG, L., FANG, J.; HUANG, Z.; XIA, H. Combustion and emission characteristics of a two stroke diesel engine opeating on alcohol. Renewable Energy, v. 30, p. 2075-2084, 2005.

[23] SAHIN, Z.; DURGUN, O. Theoretical investigation of effects of light fuel fumigation on diesel engine performance and emissions. Energy Conversion and Management, v. 48, p. 1952-1964, 2007.

[24] ABU-QUDAIS, M.; HADDAD, O.; QUDAISAT, M. The effect of alcohol fumigation on diesel engine performance and emissions. Energy Conversion \& Management, v. 41, p. 389-399, 2000.

[25] SURAWSKI, N.C.; MILJEVIC, B.; ROBERTS, B.A.; MODINI, R.L.; SITU, R.; BROWN, R.J.; BOTTLE, S.E.; RISTOVSKI, Z.D. Particle Emissions, Volatility, and toxity from an ethanol fumigated compression ignition engine. Environmental Science \& Technology, v. 44, n. 1, 2010.

[26] SAHIN, Z.; DURGUN, O.; KURT, M. Experimental investigation of improving diesel combustion and engine performance by ethanol fumigation-heat release and flammability analysis. Energy Conversion and Management, v. 89, p. 175-187, 2015.

[27] JAKOB, M; PISCHINGER, S; ADOMEIT, P; KOLBECK, A. - Glow Plug Ignition of Ethanol Fuels under Diesel Engine Relevant Thermodynamic Conditions 2010 SAE International, 2011.

[28] ARGACHOY, C.; PIMENTA, A. P. Phenomenological model of particulate matter emission from direct injection diesel engines. Journal of the Brazilian Society of Mechanical Sciences and Engineering, Brazil, 2005, v. 27, n. 3, p. 266273.

[29] ZHU, L.; CHEUNG, C. S.; ZHANG, W. G. Combustion, performance and emission characteristics of a DI diesel engine fueled with ethanol-biodiesel blends. Fuel, v. 90, p. 1743-1750, 2011.

[30] SARJOVAARA, T.; LARMI, M. Dual Fuel Combustion with an E85 ethanol/gasoline blend. Fuel, v. 139, p. 704-714, 2015

[31] FANG, Q.; FANG, J.; ZHUANG, J.; ZHEN, H. Effects of ethanol-diesel-biodiesel blends on combustion emissions in premixed low temperature combustion. Applied Thermal Engineering, v. 54, p. 541-548, 2013

[32] HEYWOOD, J. B. Internal Combustion Engine Fundamentals. 2a. ed. [S.1.]: McGraw-Hill, 2018. 1056 p. ISBN 1260116107.

[33] MULleR,C,J.; MUSCUlUS, M.P. - Glow Plug Assisted Ignition and Combustion of Methanol in an Optical DI Diesel Engine - SAE Techincal Paper 2001-01-2004 - SAE International, 2001. 


\title{
EFFECT OF AIR INTAKE TEMPERATURE ON THE DELAY OF THE IGNITION OF AN ETHANOL INTERNAL COMBUSTION ENGINE WITH IGNITION ASSISTED BY HOT SURFACE
}

\author{
Rafael Hauckewitz Todaro' ${ }^{1}$ Clayton Barcelos Zabeu², Renato Romio ${ }^{3}$, \\ Antonio Luiz Pacifico ${ }^{4}$ \\ ${ }^{1}$ todaro@usp.br; ${ }^{2}$ clayton@ maua.br; ${ }^{3}$ romio@maua.br; ${ }^{4}$ alpacifi@usp.br
}

Recent studies show that the use of ethanol for internal combustion engines promises a positive relationship between overall efficiency and the aspects related to emissions of pollutants and greenhouse gases. The main objective of the present work is to verify the influence of the intake air temperature in the combustion process of ethanol and diesel oil, specifically in the delay of ignition and the duration of combustion. The heated surface technique was used as a means to assist the ignition process of the air-ethanol mixture. General Motors' SDE 1.3 L diesel engine equipped with an open and properly adapted electronic management switchboard was used as a case study. The combustion parameters were evaluated in two cases, considering a proposed operating condition for ethanol and diesel. The results show that the properties of the combustion of the alcohol are considerably influenced by the thermodynamic state of the air in the intake stage, which differs from the behavior verified for the diesel. Under certain conditions, the ignition delay in the ethanol operation was more than $60 \%$ higher than that of diesel, and the ratio of the alcohol and diesel combustion durations is greater than $200 \%$. 